\title{
COVID-19 Death and BCG Vaccination
}

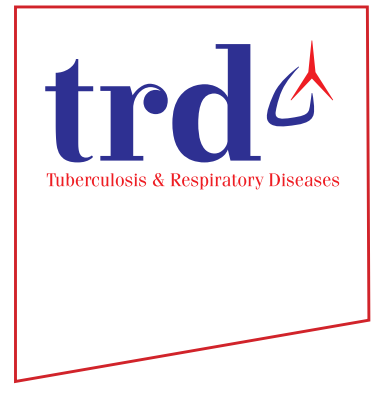

Viroj Wiwanitkit, M.D. (1)

Department of Community Medicine, Dr DY Patil University, Pune, India

Dear Editor, I would like to share ideas on the publication "COVID-19 Death and BCG Vaccination Programs Worldwide" ${ }^{\prime \prime}$. Jirjees et al. ${ }^{1}$ concluded that "it can be concluded that the early establishment of BCG vaccination policy in any country is a key element in reducing the number of COVD-19 and tuberculosis death cases." The interrelationship between coronavirus disease 2019 (COVID-19) and tuberculosis is interesting. Whether bacillus Calmette-Guerin (BCG) can help prevent the infection and mortality due to COVID-19 is an issue to be further studied. From an early report from Indochina, the co-existence between both COVID-19 and tuberculosis is possible ${ }^{2}$. In that area, Thailand, the BCG is mandatory and more than $99 \%$ coverage rate is officially declared. However, there is still a problem of COVID-19 infection and death. Focusing on infected case and death case, it appeared that all cases had BCG vaccination. There is no association between BCG vaccination history and COVID-19 infection or COVID-19 death. In fact, there is also no identified biological process of BCG that can link to the pathogenesis process of severe acute respiratory syndrome coronavirus 2 . Therefore, it seems that it might not confirm that BCG vaccination can affect the incidence of COVID-19 infection and death.

\section{Conflicts of Interest}

No potential conflict of interest relevant to this article was reported.

\section{References}

1. Jirjees FJ, Dallal Bashi YH, Al-Obaidi HJ. COVID-19 death and BCG vaccination programs worldwide. Tuberc Respir Dis 2021;84:13-21.

2. Yasri S, Wiwanitkit V. Tuberculosis and novel Wuhan coronavirus infection: pathological interrelationship. Indian J Tuberc 2020;67:264.
Address for correspondence: Viroj Wiwanitkit, M.D.

Department of Community Medicine, Dr DY Patil University, Sant

Tukaram Nagar, Pimpi Colony, Pune, Maharashtra 411018, India

Phone: 91-20-27805100, Fax: 91-20-27805100

E-mail:wviroj@yahoo.com

Received: Sep. 17, 2020

Revised: Sep. 30, 2020

Accepted: Oct. 7, 2020

Published online: Oct. 8, 2020

(c) It is identical to the Creative Commons Attribution Non-Commercial License (http://creativecommons.org/licenses/by-nc/4.0/).

Copyright (C) 2021

The Korean Academy of Tuberculosis and Respiratory Diseases. 